\title{
Predicting the presence of bacterial pathogens in the airways of primary care patients with acute cough
}

\author{
Jolien Teepe MD, Berna D.L. Broekhuizen MD PhD, Katherine Loens PhD, Christine Lammens MSc, \\ Margareta leven PhD, Herman Goossens MD PhD, Paul Little MD PhD, Chris C. Butler MD PhD, Samuel Coenen MD PhD, \\ Maciek Godycki-Cwirko MD PhD, Theo J.M. Verheij MD PhD; on behalf of the GRACE Consortium
}

Cite as: CMAJ 2017 January 16;189:E50-5. doi: 10.1503/cmaj.151364

\section{ABSTRACT \\ BACKGROUND: Bacterial testing of all patients who present with acute cough is not feasible in primary care. Further- more, the extent to which easily obtain- able clinical information predicts bacte- rial infection is unknown. We evaluated the diagnostic value of clinical examina- tion and testing for $\mathrm{C}$-reactive protein and procalcitonin for bacterial lower respiratory tract infection.}

METHODS: Through a European diagnostic study, we recruited 3104 adults with acute cough ( $\leq 28$ days) in primary care settings. All of the patients underwent clinical examination, measurement of $\mathrm{C}$-reactive protein and procalcitonin in blood, and chest radiography. Bacterial infection was determined by conventional culture, polymerase chain reaction and serology, and positive results were defined by the presence of Streptococcus pneumoniae, Haemophilus influenzae, Mycoplasma pneumoniae, Bordetella pertussis or Legionella pneumophila. Using multivariable regression analysis, we examined the association of diagnostic variables with the presence of bacterial infection.

RESULTS: Overall, 539 patients (17\%) had bacterial lower respiratory tract infection, and 38 (1\%) had bacterial pneumonia. The only item with diagnostic value for lower respiratory tract infection was discoloured sputum (area under the receiver operating characteristic [ROC] curve $0.56,95 \%$ confidence interval $[\mathrm{Cl}]$ 0.54-0.59). Adding C-reactive protein above $30 \mathrm{mg} / \mathrm{L}$ increased the area under the ROC curve to 0.62 (95\% Cl 0.59-0.65). For bacterial pneumonia, comorbidity, fever and crackles on auscultation had diagnostic value (area under ROC curve 0.68, 95\% Cl 0.58-0.77). Adding C-reactive protein above $30 \mathrm{mg} / \mathrm{L}$ increased the area under the ROC curve to $0.79(95 \% \mathrm{Cl}$ $0.71-0.87$ ). Procalcitonin did not add diagnostic information for any bacterial lower respiratory tract infection, including bacterial pneumonia.

INTERPRETATION: In adults presenting with acute lower respiratory tract infection, signs, symptoms and C-reactive protein showed diagnostic value for a bacterial cause. However, the ability of these diagnostic indicators to exclude a bacterial cause was limited. Procalcitonin added no clinically relevant information.
L ower respiratory tract infections such as acute bronchitis and pneumonia are common in primary care, with an annual incidence of 44 per 1000 in adults. ${ }^{1,2}$ A potential bacterial pathogen is isolated from $19 \%$ to $43 \%$ of patients who present to general practitioners with lower respiratory tract infection..$^{3-6}$ Bacterial infections are generally assumed to require more active treatment, including antibiotics and follow-up, because complications are more common, whereas guidelines recommend that unnecessary use of antibiotics be reduced. Therefore, it seems useful to accurately identify patients with a bacterial cause of lower respiratory tract infection, including bacterial pneumonia, to allow appropriate treatment to be started and follow-up arranged. Conversely, excluding a bacterial cause with confidence will help to avoid unnecessary antibiotic therapy and reduce antimicrobial resistance.
In primary care settings, patients with a high likelihood of bacterial lower respiratory tract infection are typically identified on the basis of easily obtainable clinical information, because microbiologic sampling and laboratory culture are time-consuming and costly, and the results are usually not available by the time a decision is needed about empiric antibiotic treatment. Moreover, routine use of chest radiography in all patients with lower respiratory tract infection to detect pneumonia in only a small proportion $\left(5 \%{ }^{7}\right)$ of patients does not balance the practical issues of exposure to radiation, time and costs. However, features that reliably predict a high probability of bacterial infection in primary care patients with lower respiratory tract infection have not been well described.

There is some evidence for the diagnostic value of signs and symptoms from studies of hospital inpatients, but these patients 
generally have more severe illness and more often have pneumonia relative to outpatients. ${ }^{8-11}$ The few observational studies of adults conducted in primary care showed that fever, headache, painful cervical lymph nodes, diarrhea and rhinitis predicted bacterial lower respiratory tract infection, but sample sizes in these studies were small. ${ }^{4,5}$

Additional testing with the inflammation markers C-reactive protein and procalcitonin is potentially useful in predicting bacterial infection. ${ }^{12}$ High levels of C-reactive protein, in addition to signs and symptoms, showed diagnostic value for pneumonia, ${ }^{7}$ and higher procalcitonin level was associated with bacterial lower respiratory tract infection among hospital inpatients. ${ }^{13}$ However, evidence for the added diagnostic value of these 2 markers for bacterial lower respiratory tract infection is limited. ${ }^{4-6}$

Here, we evaluated the diagnostic value of clinical examination and the added value of $\mathrm{C}$-reactive protein and procalcitonin for predicting which patients with lower respiratory tract infection who presented with acute cough in primary care settings had a bacterial pathogen.

\section{Methods}

\section{Design and study population}

This cross-sectional observational study was part of the GRACE-09 study (Genomics to Combat Resistance against Antibiotics in Community-Acquired Lower Respiratory Tract Infection in Europe; www.grace-Irti.org/portal/en-gb/homepage). General practitioners in 16 primary care research networks in 12 European countries collected data for patients who presented with acute cough between October 2007 and April 2010. Each of the research networks had access to a minimum of 20000 patients. Given the frequency of lower respiratory tract infections, many more eligible patients presented during the recruitment period than were invited to participate in this study; therefore, we probably did not achieve the goal of recruiting all consecutive eligible patients. Nevertheless, we assume that this situation did not result in important clinical selection bias, because clinicians reported during and after the study that the main reason for not including all eligible pa-

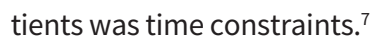

Eligible patients were at least 18 years old and presenting for the first time with a main symptom of acute or deteriorating cough (duration $\leq 28 \mathrm{~d}$ ) or any clinical presentation considered by the general practitioner to be caused by lower respiratory tract infection. Further inclusion criteria were ability to fill out study documents and provide written informed consent. Exclusion criteria were pregnancy, lactation, treatment with antibiotics in the previous month and immunodeficiency. ${ }^{14}$

\section{Clinical measurements}

The general practitioner recorded medical history details, results of the physical examination and comorbidities for each patient, using a standard case report form.

Within 24 hours of presentation, a venous blood sample was obtained for measurement of C-reactive protein and procalcitonin; these samples were transported to and analyzed at the laboratory of the University of Antwerp. C-reactive protein was measured with the conventional immunoturbidimetric method (Vitros 5.1FS chemistry system, Ortho Diagnostics, for serum samples analyzed from 2007 to September 2009; Dimension Vista System, Siemens, for serum samples analyzed from October 2009 onward). Procalcitonin was measured using a rapid sensitive assay (Kryptor procalcitonin analyzer, Brahms $\mathrm{GmbH}$ ).

A sputum sample, if the cough was productive (not available for all participants), and nasopharyngeal swab sample were collected from each patient on the day of presentation, before any antibiotic therapy was started. Sputum samples were sent to each general practitioner's local laboratory and processed immediately. Direct microscopy, gram staining and culture were performed according to a standardized protocol (as outlined in Appendix 1, available at www.cmaj.ca/lookup/suppl/doi:10.1503/cmaj.151364/-/DC1). Nasopharyngeal swabs, stored in Universal Transport Medium (Copan Diagnostics) and in skim milk medium, were sent to the laboratory of the University of Antwerp for bacterial and viral polymerase chain reaction analysis.

All patients underwent chest radiography within 7 days of presentation, preferably within 3 days. Local radiologists assessed the radiographs without access to patients' clinical information, but they did have access to previous radiographs, if available. The radiologists diagnosed pneumonia on the basis of a uniform procedure (see Appendix 2, available at www.cmaj.ca/lookup/suppl/ doi:10.1503/cmaj.151364/-/DC1). ${ }^{7}$

\section{Definition of bacterial infection}

We defined bacterial infection as the presence of Streptococcus pneumoniae, Haemophilus influenzae, Mycoplasma pneumoniae, Bordetella pertussis or Legionella pneumophila in respiratory samples or serologic evidence of Mycoplasma pneumoniae infection. We did not include Chlamydia pneumoniae, because the clinical relevance of this infection is unclear. ${ }^{3,15}$

Infection with S. pneumoniae or $\mathrm{H}$. influenzae was defined by isolation of a predominant microorganism in the sputum (ratio of leukocytes to epithelial cells $\geq 1$ as criterion for good-quality sample) or from the nasopharyngeal swab. Infection with $B$. pertussis was determined by polymerase chain reaction (from nasopharyngeal swab and sputum samples) and by measurement of immunoglobulin G (IgG) antibodies to pertussis toxin in venous blood at day 28. In addition, recent infection with $B$. pertussis was based on an antibody titre to pertussis toxin of $125 \mathrm{IU} / \mathrm{mL}$ or greater or a positive result on polymerase chain reaction in a respiratory sample. Infection with $M$. pneumoniae or L. pneumophila was determined by a positive result on polymerase chain reaction of nasopharyngeal swabs. Serologically definitive M. pneumoniae infection was defined as the presence of immunoglobulin $\mathrm{M}$ antibodies in the sample from day 1 or day 28 (or both) or by IgG seroconversion or a significant increase in IgG between days 1 and 28 .

\section{Diagnostic outcomes}

The diagnostic value of clinical examination, C-reactive protein and procalcitonin were determined for bacterial lower respiratory tract infection and separately for bacterial pneumonia. Bac- 
terial infection was deemed to be present in patients in whom any of the above-mentioned bacteria were identified. Bacterial pneumonia was defined by a diagnosis of pneumonia on chest radiography combined with the presence of any of the abovementioned bacteria.

\section{Data analysis}

All analyses were performed for the diagnostic outcomes of bacterial lower respiratory tract infection and bacterial pneumonia. According to the literature and clinical reasoning, we selected the most promising symptoms and signs, ${ }^{16}$ which we then related to the outcome by multivariable logistic regression analysis. We dichotomized age at 75 years. Using backward selection, we deleted nonsignificant items in a stepwise manner from the combination of signs and symptoms, where nonsignificance was defined as $p$ value greater than 0.10 for the log-likelihood ratio test. ${ }^{17}$ For the resulting reduced model based on signs and symptoms, we computed the area under the receiver operating characteristic (ROC) curve. By consensus, we considered an area under the ROC curve of 0.8 or greater as clinically relevant.

We compared both C-reactive protein ${ }^{7,18-21}$ and procalcitonin ${ }^{13}$ with the outcome as continuous variables. We also compared C-reactive protein with the outcome at thresholds of greater than 20 , greater than 30 and greater than $100 \mathrm{mg} / \mathrm{L} .^{7,18-21}$

Table 1: Univariable association of diagnostic variables with bacterial lower respiratory tract infection (LRTI) and bacterial pneumonia in patients presenting with acute cough in primary care

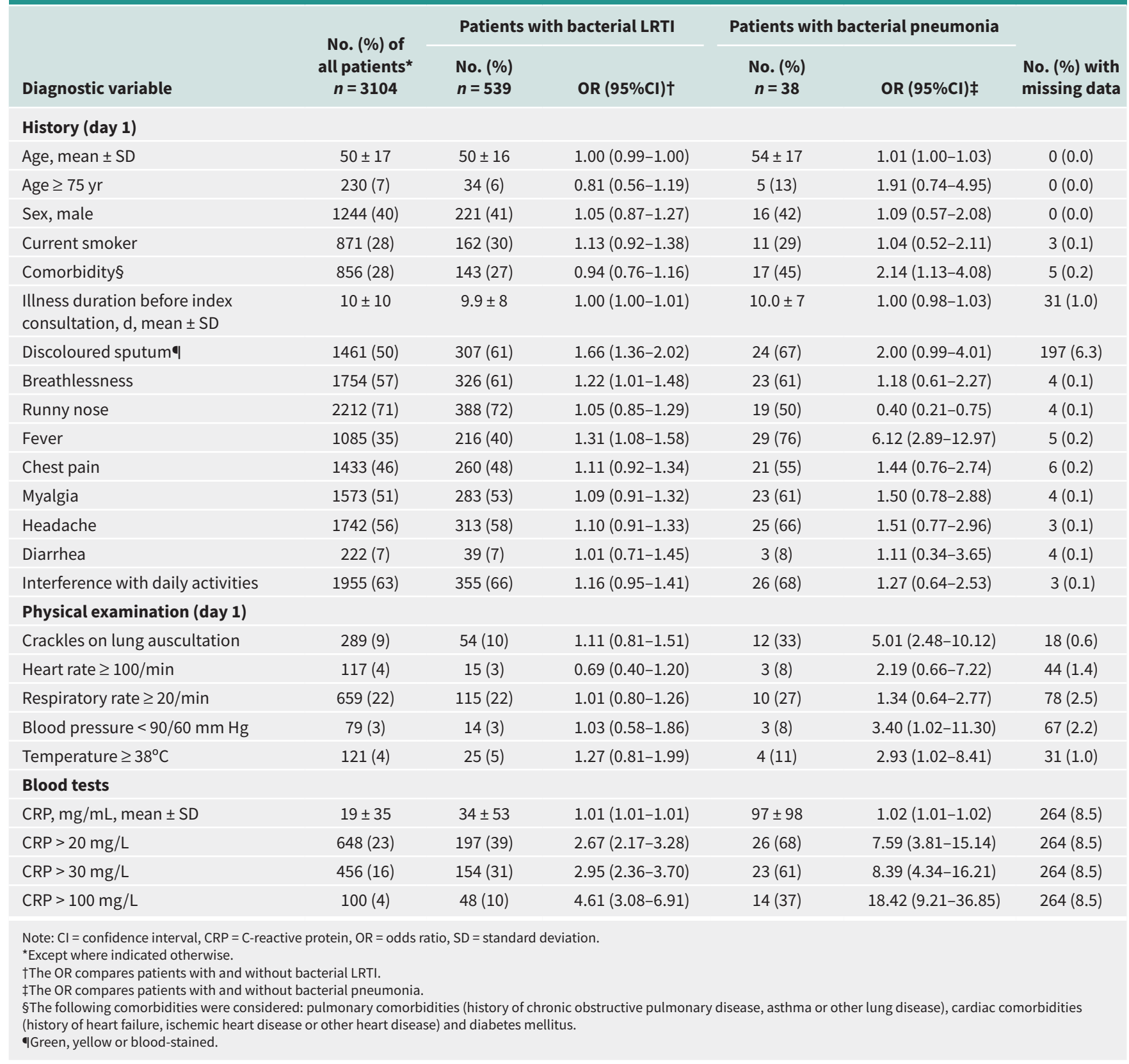


The difference in area under the ROC curve was used to evaluate increase in discrimination after adding C-reactive protein or procalcitonin to the reduced combination of symptoms and signs (with fixed regression coefficients for signs and symptoms). ${ }^{4-6,13}$ C-reactive protein was added dichotomously at above $30 \mathrm{mg} / \mathrm{L}$, because this level was previously shown to add most diagnostic value for pneumonia in cases of lower respiratory tract infection in primary care. ${ }^{7}$ Procalcitonin was added continuously, because no relevant thresholds have previously been shown in primary care. With the method of DeLong and associates, ${ }^{22}$ we calculated the $95 \%$ confidence interval $(\mathrm{Cl})$ of the ROC difference. For each model, the calibration was quantified using the Hosmer-Lemeshow test. We calculated the positive and negative predictive values for all items in the reduced signs and symptoms model that had positive or negative results, respectively, with C-reactive protein or procalcitonin added.

Finally, because we anticipated that there might have been misclassification of bacterial lower respiratory tract infection for patients with chronic obstructive pulmonary disease and for smokers (subgroups with higher levels of colonization), we performed 2 sensitivity analyses on the association between diagnostic variables and the presence of bacterial infection. One of the sensitivity analyses was restricted to patients without chronic obstructive pulmonary disease, and the other was restricted to those who did not smoke.

Data were analyzed using SPSS for Windows software (version 20).

\section{Ethics approval}

The study was approved by the medical ethics committee of the University Medical Center Utrecht.

Table 2: Independent items for diagnosing bacterial lower respiratory tract infection (LRTI) and bacterial pneumonia in patients presenting with acute cough in primary care*

\begin{tabular}{|c|c|c|}
\hline \multirow[b]{2}{*}{ Diagnostic variable } & \multicolumn{2}{|c|}{ Diagnosis; OR (95\% CI) } \\
\hline & $\begin{array}{l}\text { Bacterial } \\
\text { LRTI† }\end{array}$ & $\begin{array}{c}\text { Bacterial } \\
\text { pneumonia }\end{array}$ \\
\hline $\begin{array}{l}\text { Comorbidity (pulmonary, } \\
\text { cardiac, diabetes mellitus)§ }\end{array}$ & - & $2.05(1.03-4.09)$ \\
\hline Discoloured sputum ฯ & $1.63(1.34-1.99)$ & - \\
\hline Temperature $\geq 38^{\circ} \mathrm{C}$ & - & $2.89(0.98-8.56)$ \\
\hline Crackles on lung auscultation & - & $4.66(2.25-9.65)$ \\
\hline \multicolumn{3}{|c|}{$\begin{array}{l}\text { Note: } \mathrm{Cl}=\text { confidence interval, OR = odds ratio. } \\
\text { *Results shown had } p<0.10 \text { in multivariable analysis after backward selection; } \\
\text { nonsignificant items are not shown. } \\
\text { tVariables entered in the multivariable regression model for bacterial LRTI, based on } \\
\text { the literature: age } \geq 75 \text { years, male sex, current smoker, comorbidity, discoloured } \\
\text { sputum, temperature } \geq 38^{\circ} \mathrm{C} \text { and crackles on lung auscultation. } \\
\text { †Variables entered in the multivariable regression model for bacterial pneumonia, } \\
\text { based on the literature: age } \geq 75 \text { years, comorbidity, discoloured sputum, temperature } \\
\geq 38^{\circ} \mathrm{C} \text { and crackles on lung auscultation. } \\
\S \text { Pulmonary comorbidities were history of chronic obstructive pulmonary disease, } \\
\text { asthma or other lung disease. Cardiac comorbidities were history of heart failure, } \\
\text { ischemic heart disease or other heart disease. } \\
\text { ๆGreen, yellow or blood-stained. }\end{array}$} \\
\hline
\end{tabular}

\section{Results}

\section{Patient characteristics and diagnoses}

A total of 3104 patients were included in the GRACE study. The mean age of the 3104 participants was 50 (standard deviation [SD] 17) years, $40 \%$ were men $(n=1244)$ and $28 \%(n=871)$ were current smokers (Table 1 ). Overall, 539 participants (17\%) had a bacterial lower respiratory tract infection, and 141 participants (5\%) had radiologically confirmed pneumonia, of whom 38 (1\% of the entire sample) had bacterial pneumonia. S. pneumoniae was the most common bacterial microorganism identified (172 participants [6\%]). Other organisms identified were $H$. influenzae (167 participants [5\%]), M. pneumoniae (150 participants [5\%]), B. pertussis (95 participants [3\%]) and L. pneumophila (6 participants $[<1 \%]$ ).

\section{Diagnostic value of symptoms and signs}

The only independent predictor for bacterial lower respiratory tract infection was discoloured sputum (Table 2). This variable resulted in area under the ROC curve of 0.56 (95\% Cl 0.54-0.59).

Signs and symptoms with independent diagnostic value for bacterial pneumonia were comorbidity (pulmonary, cardiac, diabetes mellitus), fever (temperature $\geq 38^{\circ} \mathrm{C}$ ) and crackles on lung auscultation (Table 2). Combining these items resulted in area under the ROC curve of $0.68(95 \% \mathrm{Cl} 0.58-0.77)$. The result of the Hosmer-Lemeshow test for calibration of this model was 0.34 ( 1 degree of freedom, $p=0.6$ ). With all 3 independent predictors for bacterial pneumonia, the positive predictive value was $11.1 \%$ (95\% Cl 0.3-48.3; 1/9), and the negative predictive value was 99.3\% (95\% Cl 98.9-99.7; 1949/1962).

The 2 sensitivity analyses (one restricted to the 2919 patients without chronic obstructive pulmonary disease and the other restricted to the 2233 patients who did not smoke) did not lead to any change in the findings.

\section{Added diagnostic value of C-reactive protein and procalcitonin}

The mean C-reactive protein was 34 (SD 53) mg/L in patients with bacterial lower respiratory tract infection and 97 (SD 98) $\mathrm{mg} / \mathrm{L}$ for those with bacterial pneumonia (Table 1 ). Adding C-reactive protein above $30 \mathrm{mg} / \mathrm{L}$ to the symptoms and signs with independent diagnostic value resulted in area under the ROC curve of 0.62 (95\% Cl 0.59-0.65) for bacterial lower respiratory tract infection (ROC difference of $0.06,95 \% \mathrm{Cl} 0.02-0.10)$ and 0.79 (95\% Cl 0.710.87 ) for bacterial pneumonia (ROC difference of $0.11,95 \% \mathrm{Cl}$ $0.06-0.16)$. The result of the Hosmer-Lemeshow test was 0.04 (2 degrees of freedom, $p>0.9$ ) for bacterial lower respiratory tract infection and 3.62 (3 degrees of freedom, $p=0.3$ ) for bacterial pneumonia. With all independent clinical examination items and C-reactive protein above $30 \mathrm{mg} / \mathrm{L}$, the positive predictive values were $37.1 \%$ (95\% Cl 31.2\%-43.3\%; 96/259) for bacterial lower respiratory tract infection and $25.0 \%(95 \% \mathrm{Cl} 0.6 \%-80.6 \% ; 1 / 4)$ for bacterial pneumonia. The negative predictive values were 87.5\% (95\% Cl 85.4\%-89.3\%; 1006/1150) for bacterial lower respiratory tract infection and $99.7 \%(95 \% \mathrm{Cl} 99.3 \%-99.9 \%$; $1542 / 1547$ ) for bacterial pneumonia. 
Procalcitonin did not add relevant diagnostic value to the symptoms and signs model for bacterial lower respiratory tract infection or for bacterial pneumonia. The area under the ROC curve remained at $0.56(95 \% \mathrm{Cl} 0.54-0.59)$ for bacterial lower respiratory tract infection and $0.68(95 \% \mathrm{Cl} 0.58-0.77)$ for bacterial pneumonia.

\section{Interpretation}

In this study of patients with lower respiratory tract infection, the combined diagnostic value of signs and symptoms was limited. The negative predictive value for signs and symptoms and C-reactive protein level combined was $87.5 \%$, but the clinical utility was low, given the prior chance of absence of a bacterial pathogen (83\%). Although C-reactive protein added diagnostic value, procalcitonin did not.

Our findings confirm those of previous studies, in which clinical examination provided little diagnostic value for bacterial causes of lower respiratory tract infection in adults. ${ }^{3,5}$ However, Graffelman and associates ${ }^{4}$ found that headache, fever, painful cervical lymph nodes, diarrhea and rhinitis provided diagnostic value for bacterial lower respiratory tract infection in primary care (area under the ROC curve 0.79). However, their study sample was small $(n=145){ }^{4}$

Previous studies showed the relation between elevated C-reactive protein and a bacterial cause of lower respiratory tract infection. ${ }^{3,4,6}$ However, they did not analyze the added value of C-reactive protein beyond the results of clinical examination. ${ }^{3,6}$ Graffelman and associates ${ }^{4}$ reported no added diagnostic value of C-reactive protein when used with clinical examination for bacterial lower respiratory tract infection. ${ }^{4} \mathrm{Holm}$ and colleagues ${ }^{6}$ reported an association between procalcitonin and bacterial infection in primary care, but they did not include the results of clinical examination.

\section{Limitations}

One potential limitation of this study was misclassification of bacterial lower respiratory tract infection on the basis of airway bacterial colonization. We believe that such misclassification was limited, because colonization of the lower airways is unlikely in symptomatic ambulatory outpatients. Moreover, excluding patients with chronic obstructive pulmonary disease and smokers (subgroups with higher levels of colonization ${ }^{23}$ ) did not yield different findings. Finally, defining pneumonia on the basis of radiography rather than clinical features may limit generalizability to patients with pneumonia diagnosed on the basis of clinical assessment.

\section{Conclusion}

Signs, symptoms and C-reactive protein had limited clinical utility in predicting a bacterial cause for outpatients with lower respiratory tract infection. Procalcitonin added no information in the primary care setting. To support antibiotic stewardship, better markers of bacterial causes of infection should be developed.

\section{References}

1. Macfarlane JT, Colville A, Guion A, et al. Prospective study of aetiology and outcome of adult lower-respiratory-tract infections in the community. Lancet 1993;341:511-4.

2. Hak E, Rovers MM, Kuyvenhoven MM, et al. Incidence of GP-diagnosed respiratory tract infections according to age, gender and high-risk co-morbidity: the Second Dutch National Survey of General Practice. Fam Pract 2006;23:291-4.

3. Macfarlane J, Holmes W, Gard P, et al. Prospective study of the incidence, aetiology and outcome of adult lower respiratory tract illness in the community. Thorax 2001;56:109-14.

4. Graffelman AW, Knuistingh NA, le Cessie S, et al. A diagnostic rule for the aetiology of lower respiratory tract infections as guidance for antimicrobial treatment. Br J Gen Pract 2004;54:20-4.

5. Hopstaken RM, Stobberingh EE, Knottnerus JA, et al. Clinical items not helpful in differentiating viral from bacterial lower respiratory tract infections in general practice. J Clin Epidemiol 2005;58:175-83.

6. Holm A, Pedersen SS, Nexoe J, et al. Procalcitonin versus C-reactive protein for predicting pneumonia in adults with lower respiratory tract infection in primary care. Br J Gen Pract 2007;57:555-60.

7. van Vugt SF, Broekhuizen BD, Lammens C, et al. Use of serum C reactive protein and procalcitonin concentrations in addition to symptoms and signs to predict pneumonia in patients presenting to primary care with acute cough: diagnostic study. BMJ 2013;346:f2450.

8. Farr BM, Kaiser DL, Harrison BD, et al. Prediction of microbial aetiology at admission to hospital for pneumonia from the presenting clinical features. British Thoracic Society Pneumonia Research Subcommittee. Thorax 1989; 44:1031-5.

9. Metlay JP, Kapoor WN, Fine MJ. Does this patient have community-acquired pneumonia? Diagnosing pneumonia by history and physical examination. JAMA 1997;278:1440-5.

10. Hedlund J, Hansson LO. Procalcitonin and C-reactive protein levels in community-acquired pneumonia: correlation with etiology and prognosis. Infection 2000;28:68-73.

11. Foushee JA, Hope NH, Grace EE. Applying biomarkers to clinical practice: a guide for utilizing procalcitonin assays. J Antimicrob Chemother 2012;67: 2560-9.

12. van der Meer V, Neven AK, van den Broek PJ, et al. Diagnostic value of $\mathrm{C}$ reactive protein in infections of the lower respiratory tract: systematic review. BMJ 2005;331:26

13. Christ-Crain M, Jaccard-Stolz D, Bingisser R, et al. Effect of procalcitoninguided treatment on antibiotic use and outcome in lower respiratory tract infections: cluster-randomised, single-blinded intervention trial. Lancet 2004; 363:600-7.

14. van Vugt S, Broekhuizen L, Zuithoff N, et al. Incidental chest radiographic findings in adult patients with acute cough. Ann Fam Med 2012;10:510-5.

15. Hyman CL, Roblin PM, Gaydos CA, et al. Prevalence of asymptomatic nasopharyngeal carriage of Chlamydia pneumoniae in subjectively healthy adults: assessment by polymerase chain reaction-enzyme immunoassay and culture. Clin Infect Dis 1995;20:1174-8.

16. Woodhead M, Blasi F, Ewig S, et al. Guidelines for the management of adult lower respiratory tract infections - full version. Clin Microbiol Infect 2011; 17(Suppl 6):E1-59.

17. Harrell FE Jr, Lee KL, Mark DB. Multivariable prognostic models: issues in developing models, evaluating assumptions and adequacy, and measuring and reducing errors. Stat Med 1996;15:361-87.

18. Hopstaken RM, Muris JW, Knottnerus JA, et al. Contributions of symptoms, signs, erythrocyte sedimentation rate, and C-reactive protein to a diagnosis of pneumonia in acute lower respiratory tract infection. Br J Gen Pract 2003; 53:358-64.

19. Cals JW, Butler CC, Hopstaken RM, et al. Effect of point of care testing for C reactive protein and training in communication skills on antibiotic use in lower respiratory tract infections: cluster randomised trial. BMJ 2009;338:b1374. 
20. Pneumonia in adults: diagnosis and management. London (UK): National Institute for Health and Care Excellence; 2014. Available: www.nice.org.uk/guidance/ cg191 (accessed 2016 Oct. 14).

21. Little P, Stuart B, Francis N, et al. Effects of internet-based training on antibiotic prescribing rates for acute respiratory-tract infections: a multinational, cluster, randomised, factorial, controlled trial. Lancet 2013;382:1175-82.
22. DeLong ER, DeLong DM, Clarke-Pearson DL. Comparing the areas under two or more correlated receiver operating characteristic curves: a nonparametric approach. Biometrics 1988;44:837-45.

23. Rosell A, Monsó E, Soler N, et al. Microbiologic determinants of exacerbation in chronic obstructive pulmonary disease. Arch Intern Med 2005;165: 891-7.

\section{Competing interests: None declared.}

This article has been peer reviewed.

Affiliations: Julius Center for Health Sciences and Primary Care (Teepe, Broekhuizen, Verheij), University Medical Center Utrecht, Utrecht, The Netherlands; Laboratory of Medical Microbiology, Vaccine and Infectious Disease Institute (VAXINFECTIO) (Loens, Lammens, leven, Goossens, Coenen), and Centre for General Practice, Primary and Interdisciplinary Care (Coenen), University of Antwerp, Antwerp, Belgium; Primary Care Medical Group (Little), University of Southampton Medical School, Southampton, UK; Nuffield Department of Primary Care Health Sciences (Butler), University of Oxford, Oxford, UK; Faculty of Health Sciences (Godycki-Cwirko), Medical University of Lodz, Lodz, Poland
Contributors: Margareta leven, Herman Goossens, Paul Little, Chris Butler, Samuel Coenen, Maciek Godycki-Cwirko and Theo Verheij conceived and designed the study. Katherine Loens and Christine Lammens were responsible for testing all samples for bacterial infection. Jolien Teepe and Berna Broekhuizen interpreted the data and performed the analyses. Jolien Teepe, Berna Broekhuizen and Theo Verheij wrote the first draft of the manuscript, and all of the coauthors critically revised the manuscript for important intellectual content. All of the authors approved the final version for publication and agreed to serve as guarantors of the work.

Funding: This study was part of the GRACE project (www.grace-Irti.org/portal/en-gb/ homepage), funded by the Sixth Framework Program of the European Commission (reference LSHM-CT-2005-518226). The GRACE proj- ect has been financially supported through the European Science Foundation, within the framework of the Research Networking Programme TRACE (Translational Research on Antimicrobial Resistance and Community-Acquired Infections in Europe; www.esf.org/trace) and by the Research Foundation Flanders (Belgium). The current analysis was supported by the $\mathrm{SBOH}$ (www.sboh.nl), employer of Dutch general practitioner trainees. The funding sources were not involved in the design or conduct of the study, the analysis or interpretation of the data, or the writing of the article.

Accepted: Aug. 16, 2016

Early release: Oct. 24, 2016

Correspondence to: Jolien Teepe, j.teepe-2@ umcutrecht.nl 